\title{
HDL Phospholipid Measurement
}

National Cancer Institute

\section{Source}

National Cancer Institute. HDL Phospholipid Measurement. NCI Thesaurus. Code

C156513.

The determination of the amount of high-density lipoprotein phospholipid present in a sample. 